\title{
A CONTRIBUTION TO THE KNOWLEDGE OF BACTROCERA OLEAE (GMEL) IN TRAS-OS-MONTES REGION (NORTHEASTERN PORTUGAL): PHENOLOGY, LOSSES AND CONTROL
}

\author{
A. Bento \\ Escola Superior \\ Agrária Bragança, \\ 5300 Bragança
}

\author{
L. Torres \\ Universidade de \\ Trás-os-Montes \\ Alto Douro, \\ 5000 Vila Real
}

\author{
J. Lopes and R. Sismeiro \\ Direç̧ão Reg. \\ de Agricultura \\ Trás-os-Montes, \\ 5370 Mirandela
}

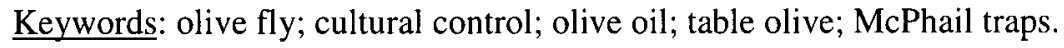

\section{$\underline{\text { Abstract }}$}

Severe damage is caused by the olive fly (Bactrocera oleae (Gmel)) in the Trás-osMontes region. In order to develop a control strategy, two olive groves for oil production ("Cobrançosa" and "Verdeal") and one for table olive ("Negrinha de Freixo") were assessed (1993-1996). The insect phenology, yield losses and fruit infestation were evaluated.

The insect's peak flight period occurred during the first half of October. Severe yield losses due to the pest occurred in 1995, reaching $19 \%$ of the total harvest. It is concluded that earlier harvesting (second half of September) can avoid substantial losses because the main period of infestation in all years occurred in October.

\section{$\underline{1 . \text { Introduction }}$}

The olive fruit fly, Bactrocera oleae (Gmel), is the principal pest of olive crops in the Mediterranean countries (Kapatos and Fletcher, 1983; Sobreiro, 1987).

In the Trás-os-Montes region, where olive growing is a major source of farmer income, the olive fly has become in recent years of serious economic relevancy to olive producers. The purpose of this work was to develop a control strategy against the pest that will prevent economic losses, without risk to the environment and human health. The phenology of the insect was studied and quantitative yield losses were assessed. The importance of manipulating the harvest data in avoiding fruit infestation by the pest was also evaluated for table olive production.

\section{Materials and methods}

Investigations were carried out in two olive groves, sited at representative olive growing areas of northeastern Portugal: Mirandela and Freixo de Espada à Cinta. Trees were of medium size, about 40-50 years old. The first for oil production (varieties "Cobrançosa" and "Verdeal"), was grown under non irrigated conditions. The other for table olive (variety "Negrinha de Freixo") has been irrigated since 1995.

To study the phenology of adult's olive fly, McPhail traps and two variations of vertical yellow sticky traps - unbaited and baited with pheromone - were used. Five traps of each kind were installed per orchard. Traps were placed $50 \mathrm{~m}$ apart at a height of approximately $2.5 \mathrm{~m}$, at the middle of the canopy and facing the south. McPhails attractant consisted of a $4 \%$ aqueous solution of biammonium phosphate containing $1 \%$ of borax solution. Pheromones caps replacement was done monthly. In Freixo, data were recorded every year from 1993 ,to 1996. In Mirandela from 1994 to 1996 on McPhail traps and in 1996, on sticky traps. All traps were checked weekly for olive fruit flies from the end of June until the harvest in Freixo and from the beginning of April until the 
harvest in Mirandela. In Mirandela and in McPhail traps the total number of adults, number of males and females was determined.

The phenology of the immatures was studied in 1995 and 1996, by inspecting samples of 25 fruits per tree from 25 olive trees chosen at random, collected every week from mid August to harvest time in Freixo, and from mid September to the harvest in Mirandela. In Mirandela in 1995, sampling was made bi-monthly. The fruits were dissected under a stereo microscope and all the stages of the olive fly were recorded.

Crop losses due to preharvest fruit drop were evaluated every year from 1993 to 1996 in Freixo and in 1995 and 1996 in Mirandela, on 25 olive trees selected at random in each orchard. From the middle of July until harvest in Freixo and from fruit setting until harvest in Mirandela, the number of dropped fruits was recorded, distinguishing the fruits that dropped due to $B$. oleae. Samples of 50 dropped fruits, or all the dropped fruits, if there were less than 50 , were analysed in the laboratory. The weight of the total fruit drop and of the fruit dropped due to olive fly was calculated at harvesting.

Yield losses were calculated by multiplying the total number of dropped fruits by the average fruit weight at harvest. The yield of each tree was recorded during harvest (end September/beginning of October in Freixo, and mid December in Mirandela).

Olive infestation was determined from samples taken from 25 trees in each orchard. The samples were collected during the last 2 months before harvest, stored in the lab and checked under stereo microscope.

\section{Results and discussion}

Marked variations were noted in the number of captured insects by different traps, in different years and locations (figures 1 and 2). McPhail traps captured more flies, but sticky traps with pheromones were more efficient when fly`s population was very low.

At Freixo, adults were already active by the end of June when traps were set. In Mirandela catches began by mid of April, except in 1995, when catches began earlier. The highest number of catches in all years and in both locations occurred during the first half of October.

The maximum number of adults captured per week (240) was recorded in 1995 in McPhail traps during the second week of October, in Mirandela, and in the first week of October in Freixo (333) flies.

Data on the phenology of immature $B$. oleae are shown in table 1. Eggs appeared from the end of August but their peak of abundance occurred by mid October. Larvae were seen continually from the end of August to the end of the period of observations. Pupae exit holes were seen also continuously from the middle of September to the end of the period of observations. Counting of male and female insects captured over $6-8$ months by McPhail traps at Mirandela over 3 years (1994-1996), indicated that several overlapping generations occurred and were reproductively active until harvest time as was found by Neuenschwander and Michelakis (1978). At Freixo, where table olives predominate, yield losses due to $B$. oleae during the four years were never serious (table 2 ). This was probably due to the fact that harvesting is performed by the end of September/beginning of October, before the peak time of infestation (figure 1). Neverthless the percent of infested fruits at harvest ranged from 4.3 to $8.8 \%$ (table 3 ), which could be considered to be significant because in table olive varieties every punctured fruit by $B$. oleae reduces the value of the crop.

In Mirandela, where olives are for oil production, and are harvested later, the weight loss due to the pest was higher than in Freixo (table 3). In 1995, the incidence of fruit drop due to $B$. oleae reached a level of $19.0 \%$ and pest infestation $59.1 \%$ of the fruit drop. In 1996, the incidence on the crop of $B$. oleae damage was lower than in the previous year $(17.5 \%)$, while $B$. oleae infestation determined only $2.3 \%$ of the fruit drop. 


\section{Acknowledgements}

Research work supported by project PAMAF IED nº 2043.

\section{$\underline{\text { References }}$}

Kapatos, E. and Fletcher, B. 1983. Establishment of economic injury levels for olive infestation by Dacus oleae in Corfu. Entomologia Hellenica, 1: 37-45.

Neusnschwander, P. and Michelakis, S. 1978. The infestation of Dacus oleae (Gmel.) (Diptera: Tephritidae) at harvest time its influence on yield and quality of olive oil in Creta. Z. Ang. Ent., 86: 420-433.

Sobreiro, J.B. 1987. First results on the use of chromotropic traps to control Dacus oleae (Gmel). Proc.of the CEC/IOBC International Symposium of Fruit Flies of Economic Importance. Rome/Italy/7-10 April 1987: 413-417.

$\mathrm{P}^{-}$and $\mathrm{P}^{+}$

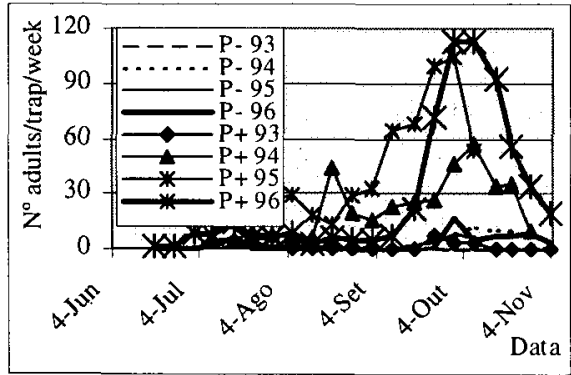

$\mathrm{McP}$

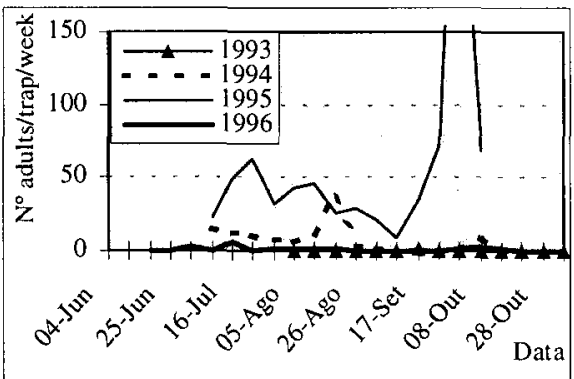

Figure 1. Mean number of captures of Bactrocera oleae adults on sticky traps with $(\mathrm{P}+)$ and without (P-) sex pheromone and in McPhail traps (McP) at Freixo de Espada à Cinta (1993-1996). Five traps were used in each case.

$\mathrm{P}^{-}$and $\mathrm{P}^{+}$

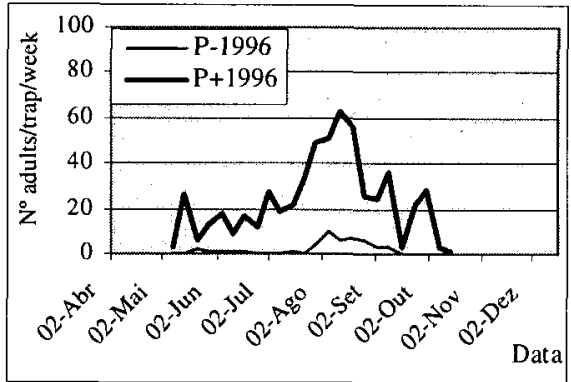

$\mathrm{McP}$

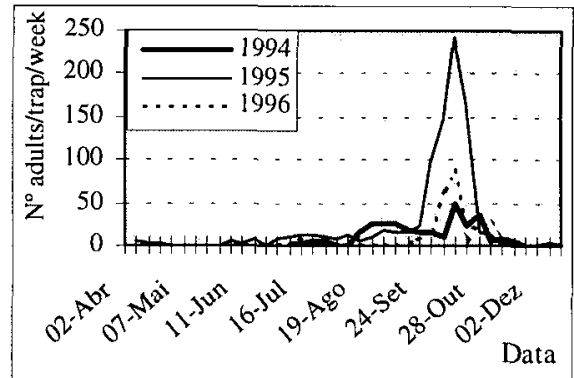

Figure 2. Mean number of captures of Bactrocera oleae adults on sticky traps with $\left(\mathrm{P}^{+}\right)$ and without pheromone $\left(\mathrm{P}^{-}\right)(1996)$ and in McPhail traps (McP) (1994-1996) at Mirandela. Five traps were used in each case. 
Table 1. Data on the life cycle of Bactrocera oleae in Freixo deEspada à Cinta and Mirandela during 1995 and 1996.

\begin{tabular}{|c|c|c|c|c|c|c|c|c|c|c|c|c|c|c|c|c|c|}
\hline \multirow[b]{3}{*}{ Date } & \multicolumn{8}{|c|}{ Freixo Espada à Cinta } & \multirow[b]{3}{*}{ Data } & \multicolumn{8}{|c|}{ Mirandela } \\
\hline & \multicolumn{4}{|c|}{1995} & \multicolumn{4}{|c|}{1996} & & \multicolumn{4}{|c|}{$\begin{array}{c}199 \\
5\end{array}$} & \multicolumn{4}{|c|}{1996} \\
\hline & $E$ & $\mathrm{~L}$ & $\mathrm{P}$ & $\mathrm{H}$ & $E$ & $\mathrm{~L}$ & $\overline{\mathrm{P}}$ & $\mathrm{H}$ & & $\bar{E}$ & $\mathrm{~L}$ & $\mathrm{P}$ & $\mathrm{H}$ & $\mathrm{E}$ & $\mathrm{L}$ & $\mathrm{P}$ & $\mathrm{H}$ \\
\hline 21 Aug. & $\overline{0}$ & $\bar{l}$ & $\overline{\overline{0}}$ & $\overline{\overline{0}}$ & $\overline{0}$ & 0 & $\overline{\overline{0}}$ & & 18 Sep. & & & & & 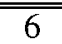 & $\overline{99}$ & 1 & $\overline{1}$ \\
\hline 28 Aug. & 1 & 1 & 0 & 0 & 0 & 0 & 0 & & 25 Sep. & 11 & 14 & 0 & 0 & & & & \\
\hline 4 Sep. & 0 & 1 & 1 & 0 & 1 & 0 & 0 & & 2 Oct. & & & & & 18 & 38 & 6 & 1 \\
\hline 11 Sep. & 1 & 5 & 0 & 0 & 2 & 1 & 0 & & 9 Oct. & 42 & 226 & 3 & 70 & 19 & 28 & 5 & 2 \\
\hline 18 Sep. & 1 & 2 & 7 & 1 & 6 & 1 & 0 & & 16 Oct. & & & & & 26 & 190 & 6 & 25 \\
\hline 25 Sep. & 4 & 2 & 3 & 2 & 4 & 25 & 0 & & 23 Oct. & 40 & 371 & 0 & 317 & 23 & 214 & 4 & 15 \\
\hline 2 Oct. & 9 & 18 & 2 & 3 & 0 & 54 & 3 & 2 & 30 Oct. & & & & & 4 & 174 & 2 & 9 \\
\hline 09 Oct. & 11 & 14 & 2 & 2 & 1 & 35 & 5 & 5 & 6 Nov. & 4 & 238 & 0 & 332 & 2 & 180 & 0 & 16 \\
\hline $16 \mathrm{Oct}$ & & & & & 5 & 52 & 9 & 9 & & & & & & & & & \\
\hline 23 Oct. & & & & & 9 & 66 & 18 & 10 & 20 Nov. & & & & & 0 & 86 & 0 & 84 \\
\hline
\end{tabular}

Legend: E - eggs; L - larvae; P - pupae; H - pupae exit holes

Table 2. Crop losses due to Bactrocera oleae in 25 olive trees (average values) in at Freixo de Espada à Cinta (F) and Mirandela (M).

\begin{tabular}{|c|c|c|c|c|c|c|}
\hline \multirow[b]{2}{*}{ Years } & \multirow[b]{2}{*}{$\begin{array}{l}\text { Fruit harvested } \\
\text { from canopy } \\
\text { weight in kg }\end{array}$} & \multirow[b]{2}{*}{$\begin{array}{l}\text { Total fruit drop } \\
\text { weight in } \mathrm{kg}\end{array}$} & \multicolumn{2}{|c|}{ Fruit drop due to $B$. oleae } & \multicolumn{2}{|c|}{ Infestation at harvest } \\
\hline & & & weight in $\mathrm{kg}$ & $\%(1)$ & $\%$ & weight in $\mathrm{kg}$ \\
\hline (F) $1993^{*}$ & 14.21 & 2.84 & 0.028 & 0.19 & 4.3 & $0 . \overline{0.61}$ \\
\hline (F) $1994 *$ & 5.20 & 4.53 & 0.229 & 4.40 & 6.2 & 0.32 \\
\hline (F) $1995 * *$ & 52.70 & 2.45 & 0.080 & 1.51 & 8.8 & 4.64 \\
\hline (F) $1996 * *$ & 37.20 & 2.67 & 0.017 & 0.05 & 7.4 & 2.75 \\
\hline (M) $1995 *$ & 24.20 & 7.77 & 4.590 & 18.96 & 84.0 & 20.33 \\
\hline (M) $1996^{*}$ & 31.10 & 4.18 & 0.730 & 2.35 & 27,0 & 8.40 \\
\hline
\end{tabular}

(1) Percentage of weight loss in relation to harvest weight; * non-irrigated trees; ** irrigated trees 